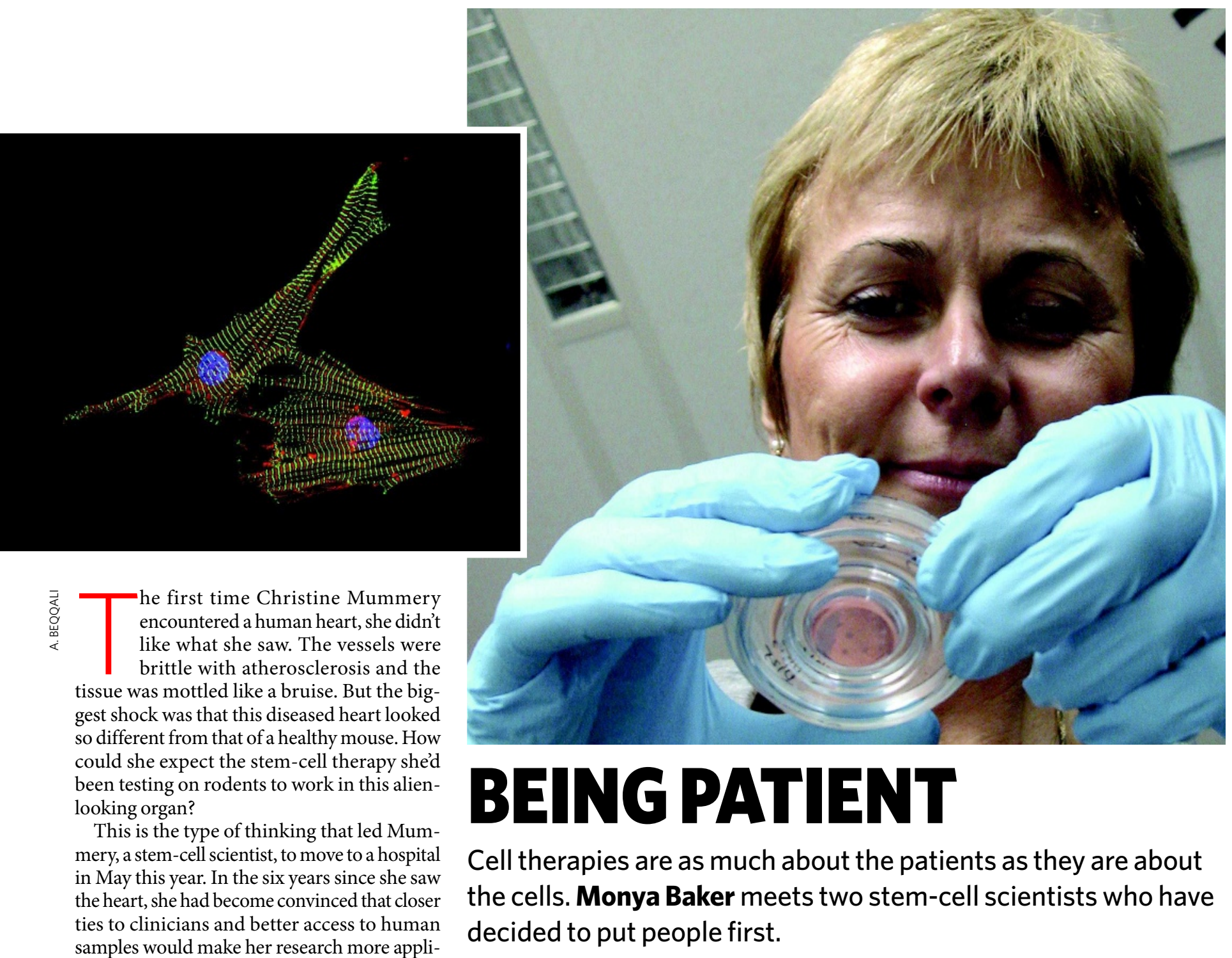
cable to patients. So she packed up her lab at the Hubrecht Institute in Utrecht, the Netherlands, and relocated to Leiden University Medical Center. "I thought we'd be better off in a clinical environment," she says. "It's so much easier if you can speak to clinicians over lunch."

Viviane Tabar also talks medicine at the table. A practicing neurosurgeon at Memorial Sloan-Kettering Cancer Center in New York, she spends two to three days a week caring for patients with brain tumours. But she thinks that surgery and the other tools that she has to help them aren't enough, so she is investigating the cells that might make brain therapies of the future. "The patient's perspective is often different from what a scientist might think," Tabar says. "They want to know what a technology can do for them on a very practical basis. So you learn to think much more pragmatically and to ask: would this really be helpful?"

Both Mummery and Tabar have veered from conventional career paths in hopes of making stem cells more useful therapeutically. They work in different countries and on different diseases. Mummery is well-established and Tabar is still early in her career. Yet both believe that

the best way to ensure that stem-cell therapies are 'translated' into patients is to be as close as possible to the patients themselves. "Some scientists could really benefit from just one or two days in the clinic," says Tabar.

Patients haven't always been the strongest focus for stem-cell researchers. Getting enough of the right cells to transplant was seen as the biggest stumbling block. That is changing with the derivation of human embryonic stem-cell lines, along with new techniques to make induced pluripotent stem (iPS) cells from patient skin biopsies. Researchers can now generate potentially limitless supplies of cells and use improved methods to grow them into the specialized types they want. The possibilities of human trials are edging nearer, and another problem is moving into focus: healing potential depends not just on the cells going into a patient, but on what they'll encounter inside.

Transplanted cells will be going into diseased bodies, says Marie Csete, scientific director of the California Institute for Regenerative Medicine (CIRM) in San Francisco, and it is the body as much as the cells that needs to be studied if researchers hope to "predict cell behaviour when we put them into a distinctly pathological environment". But few people are well versed with both stem cells and patients. "We've had a crisis in embodying someone who really understands clinical medicine and who really understands basic science in one person," says Csete. There is no question that the field needs more people like Mummery and Tabar to chart a course between an interesting concept and ready-to-test therapy, says Fred Gage, who studies neural stem cells at the Salk Institute for Biological Studies in San Diego, California.

Mummery conveys a sense of purpose. She is tall, sometimes wears her short hair spiked up, and her speech and movements are brisk. She trained as a physicist at the University of Nottingham, UK, and when Mummery later moved into biology she thought that its practitioners should "measure something rather than just look".

Mummery's quantitative approach has shown that, in some cases, stem-cell therapy may not live up to its initial promise even in animals. As a postdoc at the Hubrecht Institute she developed 
these into dopamine-producing neurons, and transplanted them back into the animals. Mice that received cell transplants derived from their own cells improved; mice that received cells derived from other mice did not. The foreign transplants seemed to trigger an immune response allowing only a few cells to survive, suggesting that human cell transplants would need to be closely matched immunologically and perhaps even derived from the patients themselves.

The results highlighted the difficulties with such therapies, but it was the paper's success that made headlines: it was the first time that cells made by therapeutic cloning were used to treat exactly the same animal from which they were derived. Tabar says it is difficult to gain recognition for the "unglamorous" work necessary to move from proof-of-principle research to a clinical application. "You could perhaps come up with a paradigm that works beautifully in animals in the lab and that puts together all these biological concepts," she says. "You can get it published, but bringing it to the patient will require a lot of mining through the details."

\section{The hard way}

Academia does not tend to reward this type of detailed investigation; recognition is based on experimental 'firsts' and high-profile publications. If a scientist-clinician is not generating a stream of prestigious papers, then pressure increases to see patients, the activity that, after all, generates revenue for a physician's institution. Does Tabar ever consider how much simpler her life would be if she switched to all clinical or all scientific work? "Every day," she responds, laughing. But, she adds, she cannot imagine giving up either pursuit.

Tabar is now studying how cell replacement might help patients whose brains have been damaged by radiation therapy, as they would be after treatment for a brain tumour. Her lab administers various radiation regimes to rats, and then supplies cells - derived from embryonic stem cells - at various stages of differentiation and at various time points, trying to find the best combinations. She insists on measuring any benefits of these treatments using behavioural tests, rather than tissue integrity alone. "It is the clinical problem that I want to address rather than the simple histological or radiographic repair of the brain."

Stem-cell researchers are not alone in finding clinical research challenging: scientists

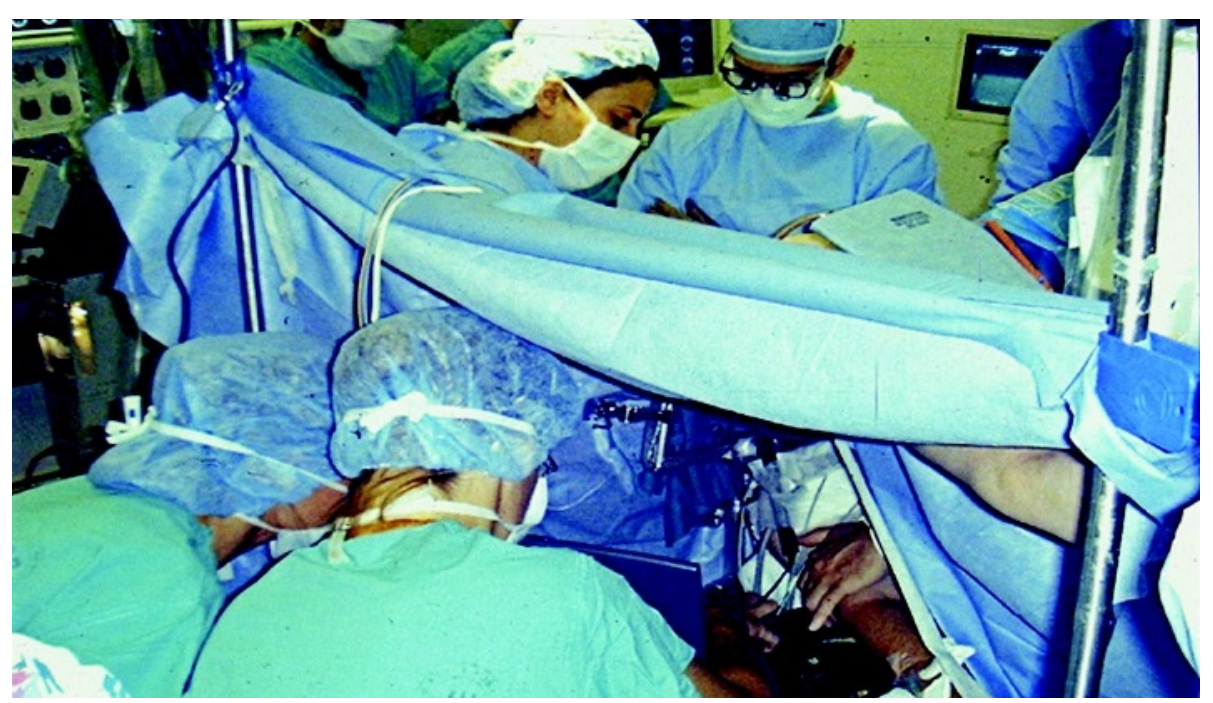

Viviane Tabar (facing right, centre of picture) says treating patients helps her to ask research questions that are relevant to therapy.

in almost every biomedical discipline are struggling to translate basic results into ones that can benefit patients. Stem-cell researchers are under particular pressure though. They must justify the massive investment made in them by funding agencies, philanthropies, and patients, such as the US\$3 billion of California taxpayer's money distributed by the CIRM.

Getting cell therapies to patients is also daunting because there is no established path to clinical approval. No treatments based on pluripotent stem cells have been approved for testing in humans, and earlier this year the US Food and Drug Administration halted plans by Californian biotech company Geron for the first trial in human patients of cells derived from embryonic stem cells. The risks for such therapies are almost impossible to assess, but the worry is that even a differentiated cell product could be unpredictable when administered to a patient, and might proliferate or transform into unwanted tissues.

Csete says that the best approach to translational research is funding collaborations or facilitating other practices that bring dis-

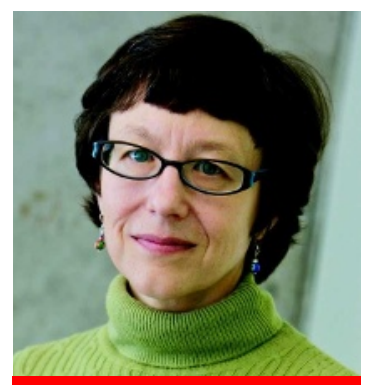

"We've had a crisis

finding someone

who understands

clinical medicine

and basic science."

- Marie Csete ease experts, clinicians and cell researchers together. The CIRM plans to announce several large, multi-year grants for such 'disease teams' later this year and has already funded just under two dozen 'planning grants' at around $\$ 50,000$ apiece to help collaborators at different institutions hammer out proposals.

The collaborative strategy seems to be working for Mummery, whose lab building is adjacent to the hospital at Leiden. There, she has access to fetal and adult human tissue and this has enabled her to try a new line of research: comparing human and mouse cardiac cells. She had good collaborations in hospitals before, she says, but people seem more willing to help colleagues within a hospital than at an unrelated institution. Mummery also benefits from the clinicians' established procedures for gathering informed consent for tissue collection.

Mummery is using the human samples to work out which molecular markers are expressed when and where in developing hearts, and she has already found that rodents can sometimes lead scientists astray. In the mouse embryo, cardiac cells express distinct markers depending on whether they will form the atrial chambers that receive blood or the ventricular chambers that pump it out. But when Mummery's team probed human fetal tissue, they found that human ventricular cells - the type that weaken in heart failure and that cell therapy might replace - actually express the markers used to identify mouse atrial cells. "That made me realize that we are trying to make heart cells from human embryonic stem cells without really knowing what the cells are."

Even as she has moved closer to the clinicians who could do cell transplants, Mummery now feels that the timelines for those transplants are lengthening. She no longer thinks that pursuing cell transplants is the most productive use of her time. Instead, she is using them to screen for drugs that can change how the cells beat in vitro, in order to understand the cause and control of cardiac arrhythmias.

The patients are just next door, but Mummery is a bit less intent on putting cells into them. For now, she's decided, there is plenty that the cells can teach her in a dish.

Monya Baker is the editor of Nature Reports Stem Cells.

\footnotetext{
van Laake, L. W. et al. Stem Cell Research 1, 9-24 (2007).

2. Laflamme, M. A. et al. Nature Biotechnol. 25, 1015-1024 (2007).

3. van Laake, L. W. et al. Circ. Research 102, 1008-1010 (2008)
}

4. Tabar, V. et al. Nature Med. 14, 379-381 (2008) 